Article

\title{
Direct Observations of the Structural Properties of Semiconducting Polymer: Fullerene Blends under Tensile Stretching
}

\author{
Mouaad Yassine Aliouat ${ }^{1,2} \mathbb{D}^{\circ}$, Dmitriy Ksenzov ${ }^{3}\left(\mathbb{D}\right.$, Stephanie Escoubas ${ }^{1, *}$, Jörg Ackermann ${ }^{4}$, \\ Dominique Thiaudière ${ }^{5}$, Cristian Mocuta ${ }^{5}$, Mohamed Cherif Benoudia ${ }^{2}(D)$ David Duche ${ }^{1}$, \\ Olivier Thomas ${ }^{1}(\mathbb{D})$ and Souren Grigorian ${ }^{3, *(\mathbb{D})}$ \\ 1 Aix Marseille Univ, U. Toulon, CNRS, IM2NP (Institut Matériaux Microélectronique et Nanosciences \\ de Provence), Campus St-Jérôme, 13397 Marseille CEDEX 20, France; \\ mouaad-yassine.aliouat@im2np.fr (M.Y.A.); david.duche@univ-amu.fr (D.D.); \\ olivier.thomas@im2np.fr (O.T.) \\ 2 Ecole Nationale Supérieure des Mines et de la Métallurgie, L3M, Annaba, Sidi Amar W129, Algeria; \\ mohamed-cherif.benoudia@ensmm-annaba.dz \\ 3 Institute of Physics, University of Siegen, D-57068 Siegen, Germany; ksenzov@physik.uni-siegen.de \\ 4 Aix-Marseille University, CNRS, CINAM, 13007 Marseille, France; jorg.ackermann@univ-amu.fr \\ 5 Synchrotron SOLEIL, L'Orme des Merisiers Saint-Aubin, CEDEX BP 48, 91192 Gif-sur-Yvette CEDEX, France; \\ dominique.thiaudiere@synchrotron-soleil.fr (D.T.); cristian.mocuta@synchrotron-soleil.fr (C.M.) \\ * Correspondence: stephanie.escoubas@univ-amu.fr (S.E.); grigorian@physik.uni-siegen.de (S.G.)
}

Received: 15 June 2020; Accepted: 6 July 2020; Published: 10 July 2020

\begin{abstract}
We describe the impact of tensile strains on the structural properties of thin films composed of PffBT4T-2OD $\pi$-conjugated polymer and $\mathrm{PC}_{71} \mathrm{BM}$ fullerenes coated on a stretchable substrate, based on a novel approach using in situ studies of flexible organic thin films. In situ grazing incidence X-ray diffraction (GIXD) measurements were carried out to probe the ordering of polymers and to measure the strain of the polymer chains under uniaxial tensile tests. A maximum $10 \%$ tensile stretching was applied (i.e., beyond the relaxation threshold). Interestingly we found different behaviors upon stretching the polymer: fullerene blends with the modified polymer; fullerene blends with the 1,8-Diiodooctane (DIO) additive. Overall, the strain in the system was almost twice as low in the presence of additive. The inclusion of additive was found to help in stabilizing the system and, in particular, the $\pi-\pi$ packing of the donor polymer chains.
\end{abstract}

Keywords: conjugated polymer and blends; in situ GIXD; additive; structure; strain

\section{Introduction}

One of the important research directions in the field of organic electronics is the development of stretchable/flexible electronics, which has attracted a lot of attention with a huge potential for numerous practical applications in different fields and daily life [1-3]. With the recent development of the flexible organic electronics, the performances of devices based on organic semiconducting molecules and polymers, such as organic light-emitting diodes (OLEDs), organic field effect transistors (OFETs) and organic solar cells (OSCs), have remarkably increased [4-8].

OSCs can be fabricated on large areas using low-cost roll-to-roll manufacturing techniques and, thus, represent an interesting alternative to conventional silicon solar cells $[7,8]$, especially for nomadic applications and everyday connected objects, but also to construction, transport, urban furniture, etc. Recently, stretchable OSCs have demonstrated high potential as an energy source for the domain of flexible electronics [9-11]. The photoactive layer of an OSC is based on bulk heterojunctions, created 
by blending conjugated polymers and small molecule acceptors that provide low bandgap light absorption, high power conversion efficiency (PCE), appropriate energy level positions and quite high carrier mobilities $[12,13]$. In the last decade, tremendous efforts have been focused on the synthesis of new low bandgap donor polymers (e.g., PffBT4T-2OD polymer, commonly called PCE11) [14,15] and non-fullerene organic acceptors. The PCE of polymer-based solar cells has significantly increased and reached $16.5 \%$ in 2019 [16]. In most cases, additives, such as 1,8-diiodooctane (DIO), are used to improve nanoscale morphology and, thus, the performance of the organic solar cells $[17,18]$. DIO is a high boiling point additive used generally to dissolve $\mathrm{PC}_{71} \mathrm{BM}$ aggregates selectively [19], which improves the miscibility of fullerene molecules in PCE11. The additive slows down the formation of fullerene aggregates during the drying of the polymer blend, which makes the penetration of fullerene molecules between the chains of the donor polymer easier [20]. This effect was observed on the blend TQ1:PC ${ }_{71} \mathrm{BM}$ (TQ1:Poly[[2,3-bis(3-octyloxyphenyl)-5,8-quinoxalinediyl]-2,5-thiophenediyl]) [21] and on the PCE11:PC ${ }_{71} \mathrm{BM}$ mixture [19].

There are a lot of scientific efforts aimed at understanding and improving the microstructure of polymer-based OSCs, such as solution optimization [22,23], employing low volatile additives [24-26] and thermal annealing [27]. Moreover, the direct observation of film crystallization/formation during solvent evaporation gives insight into the phase separation in blends and allows correlating observed phenomenon to electrical properties [28], thus controlling polymer chain crystallization and fullerene molecule aggregation as a function of the blend concentration. In parallel, several methods have been developed with compact instrumentations, capable of tracking the crystallization process of semiconducting polymers and blends at synchrotron radiation facilities [8,29-31]

Taking into account this tremendous progress in understanding the structural evolution during the solution processing [31,32], the development of flexible and intrinsically stretchable organic conductors is very promising for the realization of emerging novel devices [33].

The commonly used approach is to probe thin films after stretching where the deformation of materials at a fixed value of strain can induce the anisotropy of the structural and morphological properties [34,35]. During the stretching process itself, the molecular structure and crystallinity can be strongly modified [36]. Moreover, if a phase transition takes place, it can dramatically influence the structural and electrical properties of the thin film [37]. Stretchable or wearable working devices rely on the knowledge and reproducibility of the evolution of electronic and optical properties under mechanical load $[10,38,39]$. It is worth noting that electrical transport measurements can also be a sensitive probe for strain-induced defects [40]. In our recent work, in situ grazing incidence X-ray diffraction (GIXD) studies were carried out to measure the structural parameters of pristine PCE11 polymer under uniaxial tensile load [41]. It was found that, after $15 \%$ of stretching a partial strain, relaxation takes place together with massive crack propagation. To go further towards relevant materials for OPV application, we expand on in situ GIXD metrology to the PCE11 blends with a focus on the impact of blending fullerenes inside the polymer on the mechanical properties. Furthermore, we put a particular focus on the role of additives under an applied strain in the pre-cracking regime, as additives not only improve device performances, but may also impact the nanoscale morphology and organization of the blended layers.

\section{Materials and Methods}

PCE11 (PffBT4T-2OD) (batch: YY11246CB) and PC 71 BM (99.5\%) were purchased from 1-Material Inc. (Dorval, Quebec, Canada). PDMS stretchable substrate was prepared by spin coating of Sylgard 184 Silicone, obtained from Dow Corning (SAMARO, Lyon, France) using the ratio elastomer:hardener (10:1). After the degreasing of the polydimethylsiloxane (PDMS), using acetone, ethanol and water in an ultrasonic bath for $15 \mathrm{~min}$ for each bath and drying by argon flux gas, PDMS was fixed on a glass support, and the surface was activated by UV-ozone treatment at $80^{\circ} \mathrm{C}$ for $10 \mathrm{~min}$ to improve the coatability. 
The coating operation was carried out under an argon atmosphere inside a glove box. The blended layers with a thickness of $300 \mathrm{~nm}$ were spin coated at $1000 \mathrm{rpm}$ from a chlorobenzene (CB):dichlorobenzene (DCB) (1:1) mixed solution of PCE11:PC ${ }_{71} \mathrm{BM}$ with a mixture ratio of 1:1.2 wt.\% (33 mg/mL in total). For layers with 1,8-Diiodooctane (DIO), 3\% DIO was added to the solution one hour before the coating.

The temperature of the polymer inks (with and without DIO) was kept at $110{ }^{\circ} \mathrm{C}$ and the substrate was heated at $100^{\circ} \mathrm{C}$ during the spin coating operation. After coating, the layer was dried at $100^{\circ} \mathrm{C}$ for $15 \mathrm{~min}$ and then the sample was immediately removed after drying.

Pure PCE11 layers were spin coated on glass and PDMS substrates at $1000 \mathrm{rpm}$ from a CB solution of $15 \mathrm{mg} / \mathrm{mL}$ PCE11 concentration, the PCE11 ink was agitated at $110{ }^{\circ} \mathrm{C}$ for more than one hour in a glove box.

The structural properties of the thin flexible films were investigated by GIXD technique at two different beamlines:

(i) DiffAbs beamline of SOLEIL synchrotron (Saint-Aubin, France) using a wide-area 2D XPAD detector $(560 \times 960$ pixels of $130 \mu \mathrm{m})$ [42]. The measurements are recorded from the XPAD detector at different $\alpha_{\mathrm{f}}$ ranges in the out-of-plane direction, as shown in Figure 1 (Positions 1 and 2). The distance sample-detector was $450 \mathrm{~mm}$.

(ii) BL9 beamline of DELTA synchrotron radiation facility at TU Dortmund, Dortmund, Germany, using a 2D image plate (MAR345) with a resolution of $100 \mu \mathrm{m} /$ pixel [43]. The distance sample-detector was $394 \mathrm{~mm}$.

For both experiments, $\mathrm{X}$-ray photon energy of $15 \mathrm{keV}$ was employed and a grazing incidence angle of $0.07^{\circ}$ was chosen to probe the scattered signal from films. A photodiode point detector was used for aligning the sample at each stretching position.

A specially designed in situ stretching chamber allowed us to stretch thin films in a controlled way with a given amount of applied stretch and number of steps, as shown in Figure 1a. For each stretching step, the thin films were aligned prior to recording the GIXD patterns. The scattered signal was collected using a 2D detector. The sample surface was placed nearly horizontal, inclined by an incident angle $\alpha_{i}=0.07^{\circ}$. The exit angle was denoted $\alpha_{\mathrm{f}}$ at the azimuth angle $\varphi$. Figure $1 \mathrm{a}$ shows the out-of-plane $\left(\mathrm{q}_{\mathrm{z}}\right)$ and in-plane $\left(q_{x y}\right)$ directions of the two-dimensional GIXD pattern. The molecular structure of PCE11 and $\mathrm{PC}_{71} \mathrm{BM}$ molecules, and the schematic representation of the two main preferential orientations of the polymer chains (i.e., edge-on and face-on configurations with the backbone plane oriented perpendicular and parallel to the substrate, respectively), are depicted in Figure $1 \mathrm{~b}$.

\section{a)}

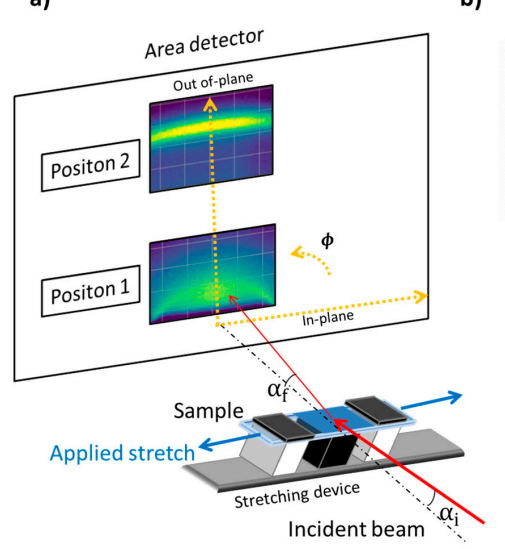

b)

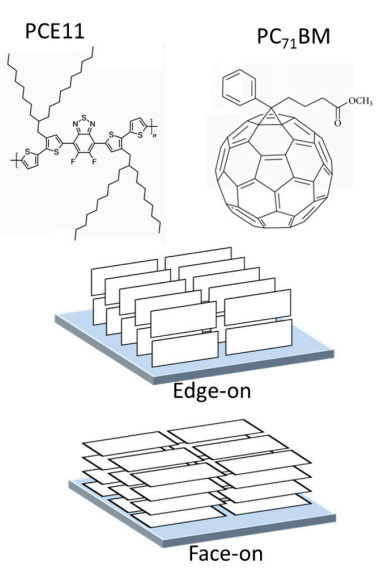

Figure 1. (a) Schematic view of the experimental setup for the GIXD experiments. (b) Molecular structure of PCE11 and $\mathrm{PC}_{71} \mathrm{BM} —$ schematic representation of edge-on and face-on orientations. 


\section{Results and Discussions}

\subsection{Structural Properties before Stretching}

Typically, spin coated semi-crystalline polymers favor edge-on orientation with the $\pi-\pi$ stacking and conjugated backbone directions parallel to the substrate, whereas blending the donor polymer with fullerene acceptors leads to the co-existence of both edge-on and face-on orientations [19,20,44].

Our recent study on the structure of pristine PCE11 revealed that spin-coated layers on both rigid and stretchable substrates, are mostly edge-on oriented with more pronounced order and crystallinity for those coated on glass [41]. The present work is focused on PCE11 blends with fullerene molecules investigated via in situ GIXD under tensile stretching.

A 2D GIXD pattern for pristine PCE11 coated on glass is shown in Figure 2a. For pristine PCE11 film, the 2D pattern shows the edge-on orientation with the lamellar stacking perpendicular to the glass substrate. Such orientation results in a strong h00 series along the out-of-plane direction, and for in-plane direction, a pronounced 010 peak associated with $\pi-\pi$ stacking, as shown in Figure 2 a. The position of the 100 lamellar peak is at $3 \mathrm{~nm}^{-1}$ corresponding to a spacing of $2.09 \mathrm{~nm}$, while the $\pi-\pi$ stacking peak is centered at $17.5 \mathrm{~nm}^{-1}$ corresponding to a $\pi-\pi$ spacing of $0.36 \mathrm{~nm}$, which is in good agreement with the literature [15,45]. Initial GIXD patterns (before stretching) for the blends on PDMS are shown in Figure 2b,c. Interestingly, the lamellar stacking is flipped by $90^{\circ}$, resulting in dominating face-on orientation. In this case the lamellar 100 peak is mainly visible in-plane at $2.9 \mathrm{~nm}^{-1}(\mathrm{lamellar}$ spacing of $2.17 \mathrm{~nm}$ ) whereas 010 peaks appear only in the out-of-plane direction at $17.5 \mathrm{~nm}^{-1}$, as shown in Figure 2b,c. Additionally, broad PDMS and PC 71 BM halos, respectively, centered at $8.5 \mathrm{~nm}^{-1}$ and $13 \mathrm{~nm}^{-1}$ are visible.
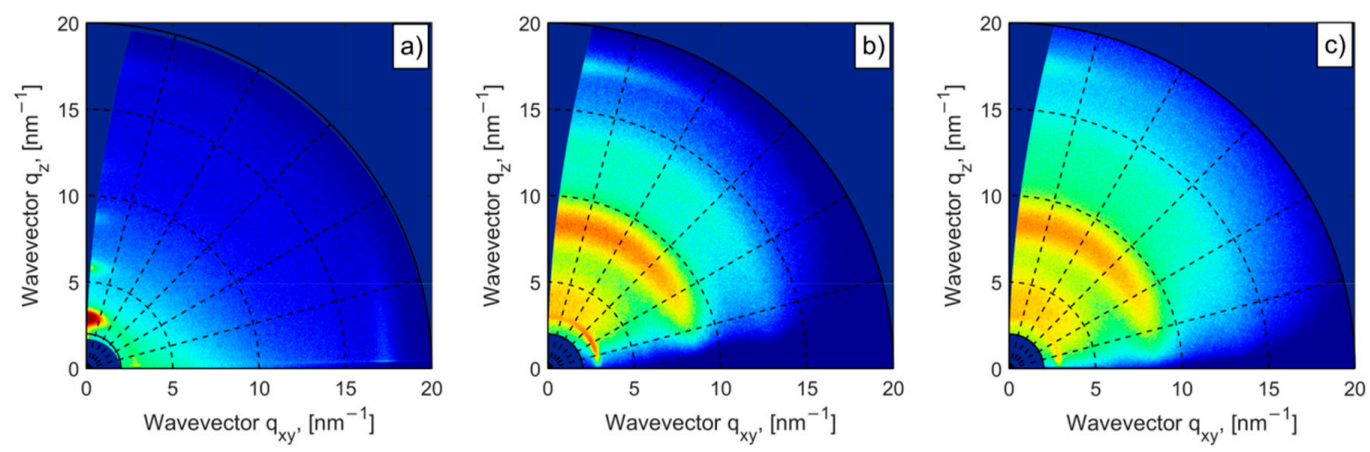

Figure 2. Two-dimensional GIXD patterns of (a) pristine PCE11 film coated on glass substrate and PCE11:PC 71 BM blend (b) with DIO, (c) without DIO, coated on PDMS substrates.

Assuming the homogeneous distribution of lamellar spacings, the full width at half-maximum (FWHM) is mainly related to the finite domain size, as characterized by the coherence length, which is inversely proportional to the FWHM, according to the Scherrer equation [46]. Calculated domain sizes for each sample are given in Table 1. The FWHM corresponding to the in-plane 100 peak of pristine PCE11 is almost twice broader than for the PCE11:PC 71 BM blends. Similar behavior was observed comparing pure PCE11 polymer with PCE11:PCBM blends on hard supports [45]. In this study, the increase in the size of ordered domains was related to the presence of PCBM molecules in the PCE11 ordered phases, forming less perfect but larger area ordered domains.

Furthermore, our study is focused on the polymer:fullerene blends on the flexible substrates. To understand the role of the additive on the crystalline organization of the PCE11 and PC 71 BM blends, we have compared the line profiles extracted from $2 \mathrm{D}$ patterns, as shown in Figure $2 b, c$, along to the out-of-plane $\left(q_{z}\right)$ and in-plane $\left(q_{x y}\right)$ cuts. These profiles are shown in Figure $3 a, b$, respectively, and confirm dominating face-on orientation. The FWHM of the in-plane 100 peak for blend with DIO is 1.2 larger than that for blend without DIO (same for the out-of-plane 010 peak), indicating smaller ordered domains, even though the degree of the $\pi-\pi$ packing is improved after the addition of DIO, 
as shown in Table 1 . This might also be due to the existence of bigger $\mathrm{PC}_{71} \mathrm{BM}$ molecules in the blend without DIO, forming less crystalline but larger area PCE11-ordered domains, as reported in [45]. With the addition of DIO, $\mathrm{PC}_{71} \mathrm{BM}$ aggregates dissolve better [19], leading to better crystallized but smaller PCE11 ordered domains.

Table 1. (100) and (010) domain sizes of pure PCE11 film, coated on glass, and PCE11:PC 71 BM films (with and without DIO additive) coated on PDMS.

\begin{tabular}{ccccc}
\hline \multirow{2}{*}{ Polymer } & \multicolumn{2}{c}{ 100 Domain Size $(\mathbf{n m})$} & \multicolumn{2}{c}{ 010 Domain Size $(\mathbf{n m})$} \\
\cline { 2 - 5 } & OOP & IP & OOP & IP \\
\hline Pristine PCE11 & 12.9 & 9.6 & 4.46 & 4.22 \\
Blend with DIO & 11.3 & 11 & 6.75 & - \\
Blend without DIO & 13.56 & 13.2 & 8.1 & - \\
\hline
\end{tabular}

A comparison of the azimuthal distribution for the blends processed with and without DIO is shown in Figure 3c,d, where the blend with DIO reveals more pronounced face-on orientation.

a)
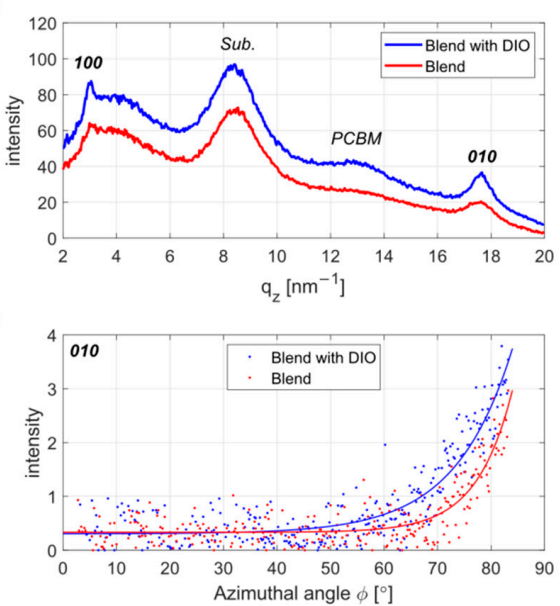

b)

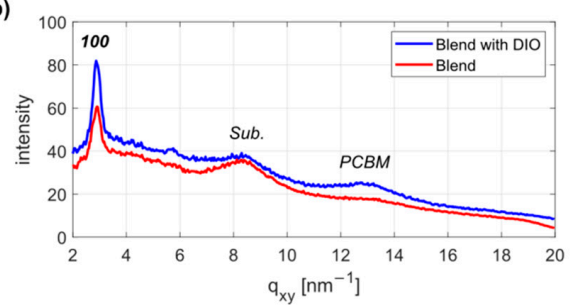

d)

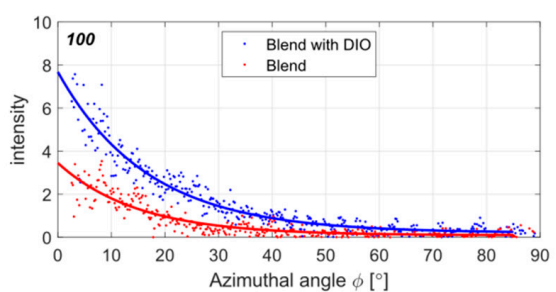

Figure 3. Out-of-plane (a) and in-plane (b) line profiles for PCE11:PC ${ }_{71} \mathrm{BM}$ blend (red circles) and PCE11:PC ${ }_{71}$ BM blend with DIO (blue circles) on the PDMS; the azimuthal profiles for the 010 (c) and 100 (d) peaks, respectively.

The ordering of the donor polymer is a very important parameter affecting the charge transport and interconnectivity within the blends, thus improving the solar cell performance [47]. The face-on crystallization of PCE11 chains is favorable for the charge transport in the direction across the active layer [15]. We observe here that face-on orientation as shown, for example, by the intensity of $\pi-\pi$ stacking peak 010 is more pronounced for the blend film with DIO. Similar findings were reported in [48], supporting the idea that DIO is beneficial to the crystallinity of PCE11 chains in blends, resulting in better charge transport.

\subsection{In Situ Structural Studies Under Stretching}

In this section, we employ in situ GIXD metrology to monitor the microstructure of the polymer:fullerene blends upon stretching. Because of the increased scattering background on the flexible support, which makes it difficult to resolve the PCBM halo, we are focusing on the most intense PCE11 peaks. We compared the structural changes of the PCE11:PC 71 BM and PCE11:PC $71 \mathrm{BM}_{\text {with }}$ DIO blends upon stretching under grazing incidence geometry. The samples were uniaxially stretched during a tensile test starting from $1 \%$ with steps of $2 \%$ up to $7 \%$ and finally reaching $10 \%$. For each step, the GIXD patterns have been recorded for the same angle of incidence of $0.07^{\circ}$. The maximum intensity of the in-plane 100 peak for the blended sample without additive was about two-times lower than for 
the one with DIO. To compensate the geometric effects and experimental constraints, we assume that the PDMS support provides an isotropic intensity distribution and the scattering ring from PDMS is independent of the azimuthal angle. Therefore, each pattern has been normalized on the corresponding PDMS ring. The normalized data show different trends for the blends processed with and without DIO upon stretching. Figure $4 \mathrm{a}$ shows the strain evolution $(\varepsilon)$, calculated from Equation (1), of the $\pi-\pi$ stacking distance $d$ corresponding to the out-of-plane 010 peak position for the blends without and with DIO.

$$
\varepsilon[\%]=100\left(d-d_{0}\right) / d_{0}
$$

Strain evolution appears clearly different for both blends—the PCE11:PC 71 BM processed without DIO shows an almost monotonous increase in tensile perpendicular strain up to $0.8 \%$ upon stretching. For the blend processed with DIO, the trend is opposite, resulting in a compressive perpendicular strain upon stretching.
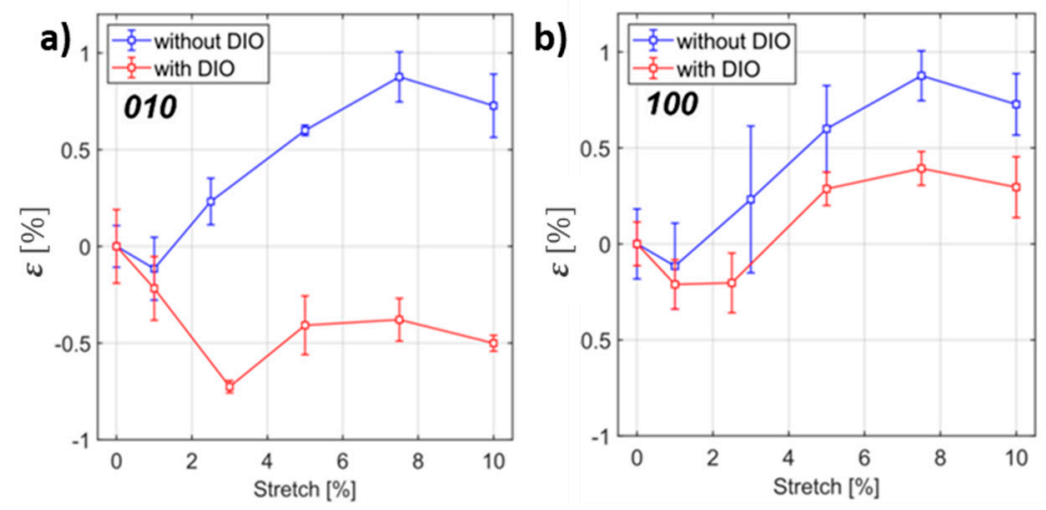

Figure 4. The strain evolution of the out-of-plane $010 \pi-\pi$ spacing (a) and in-plane 100 lamellar spacing (b) as a function of the applied stretch for the PCE11:PC 71 BM blends without (blue) and with DIO (red).

Figure $4 \mathrm{~b}$ shows the strain evolution of the polymer lamellar distance, corresponding to the in-plane 100 peak, for the blends with and without DIO. The strain evolution is almost similar for both blends. For the PCE11:PC 71 BM blend, there is an almost monotonous increase in tensile strain up to $0.8 \%$ upon stretching (the same order of magnitude found in a previous study for pristine PCE11 [41]), whereas for the blend with DIO, this increase is smaller by a factor of two. Comparing the features for the 010 and 100 peaks, their behaviors are different—-the PCE11:PC 71 BM blend exhibits expansion in both directions. On the other hand, the PCE11:PC ${ }_{71} \mathrm{BM}$ blend with DIO shows a compressive out-of-plane strain. A possible stabilization of the systems during first few steps of the stretching might be a reason for the higher compressive strain at $3 \%$ of stretching.

The FWHM of the 010 peak for the blend with DIO remains unchanged upon stretching. For the blend without DIO we found a monotonous increase in the FWHM, reaching a similar value as that of the PCE11:PC 71 BM blend with DIO (not shown here). Similar to the 010 peak, the 100 FWHM for the PCE11:PC 71 BM blend without DIO remains unchanged upon stretching. For the blend with DIO we found a monotonous decrease in the FWHM, reaching a similar value as that of the PCE11:PC 71 BM blend.

From our recent findings on pristine PCE11 coated on PDMS [41], the initial orientation of PCE11 chains is mostly edge-on. In the present work, we found that blending PCE11 with $\mathrm{PC}_{71} \mathrm{BM}$ molecules leads to the reversed orientation (face-on). This face-on orientation becomes more pronounced after the addition of DIO. The switch in orientation from edge-on to face-on is clearly observed to influence the mechanical behavior of PCE11 chains. When the chains are edge-on oriented, tensile tests revealed that in the out-of-plane direction, the chains undergo increasing compressive strain (negative values of strains) until $10 \%$ of stretching, in agreement with the Poisson effect. On the other hand, the face-on oriented chains are undergoing expansion (positive values of strains) along both directions. 


\section{Conclusions}

In comparison to pristine PCE11 films with dominating edge-on orientation, polymer:fullerene blends have shown a $90^{\circ}$ switch with preferential face-on orientation. For the PCE11:PC ${ }_{71}$ BM blends, the inclusion of the DIO additive further improves the microstructure and enhances face-on orientation.

In situ studies during tensile testing of PCE11:PC 71 BM processed with and without additives showed different mechanical behavior. In the case of the PCE11:PC ${ }_{71} \mathrm{BM}$ blend, only tensile strain has been observed, for the blend with DIO, we found a compressive out-of-plane strain associated with the $\pi-\pi$ conjugation. It is also worth noting that the blends with DIO were almost by a factor of two less strained under the same stretching conditions. The implications of these findings, based on the inclusion of additives, could be beneficial for the flexibility and stability of organic photovoltaic devices. These in situ X-ray scattering studies during mechanical testing allow for the direct correlation of the structural and mechanical properties of organic materials for flexible electronics.

Author Contributions: Conceptualization, M.Y.A., S.E., J.A. and S.G.; methodology, M.Y.A., S.E., M.C.B., D.D. and S.G.; software, M.Y.A., D.K. and C.M.; validation, S.E. and S.G.; formal analysis, M.Y.A., D.K. and C.M.; investigation, M.Y.A., S.E., C.M., O.T. and S.G.; resources, J.A., D.T. and C.M.; data curation, M.Y.A., D.K., D.T. and C.M.; writing—original draft preparation, A.M.Y. and S.G.; writing—review and editing, S.E., J.A., O.T. and S.G.; visualization, M.Y.A., D.K. and S.G.; supervision, S.E., M.C.B. and D.D.; project administration, S.E., M.C.B. and S.G.; funding acquisition, S.E., M.C.B., O.T. and S.G. All authors have read and agreed to the published version of the manuscript.

Funding: We are grateful for financial support from the DAAD-PROCOPE (project No. 57211900, Campus France 35484SE) and PHC-Tassili (Project No. 17MDU994).

Acknowledgments: We acknowledge the BL9 beamline scientists at the DELTA synchrotron (Dortmund, Germany) and Synchrotron SOLEIL (Saint-Aubin, France) for supplying the beam-time for these experiments.

Conflicts of Interest: The authors declare no conflict of interest.

\section{References}

1. Liu, Y.; Wang, H.; Zhao, W.; Zhang, M.; Qin, H.; Xie, Y. Flexible, Stretchable Sensors for Wearable Health Monitoring: Sensing Mechanisms, Materials, Fabrication Strategies and Features. Sensors 2018, $18,645$. [CrossRef] [PubMed]

2. Sirringhaus, H.; Brown, P.J.; Friend, R.H.; Nielsen, M.M.; Bechgaard, K.; Langeveld-Voss, B.M.W.; Spiering, A.J.H.; Janssen, R.; Meijer, E.W.; Herwig, P.; et al. Two-dimensional charge transport in self-organized, high-mobility conjugated polymers. Natural 1999, 401, 685-688. [CrossRef]

3. McCulloch, I.; Heeney, M.; Bailey, C.; Genevičius, K.; Macdonald, I.; Shkunov, M.; Sparrowe, D.; Tierney, S.; Wagner, R.; Zhang, W.; et al. Liquid-crystalline semiconducting polymers with high charge-carrier mobility. Nat. Mater. 2006, 5, 328-333. [CrossRef] [PubMed]

4. Sirringhaus, H. 25th Anniversary Article: Organic Field-Effect Transistors: The Path Beyond Amorphous Silicon. Adv. Mater. 2014, 26, 1319-1335. [CrossRef] [PubMed]

5. Hösel, M.; Dam, H.F. Development of Lab-to-Fab Production Equipment Across Several Length Scales for Printed Energy Technologies, Including Solar Cells. Energy Technol. 2015, 3, 293-304. [CrossRef]

6. Oh, J.Y.; Kim, S.; Baik, H.-K.; Jeong, U. Conducting Polymer Dough for Deformable Electronics. Adv. Mater. 2015, 28, 4455-4461. [CrossRef]

7. Brabec, C.J.; Gowrisanker, S.; Halls, J.J.M.; Laird, D.; Jia, S.; Williams, S.P. Polymer-Fullerene Bulk-Heterojunction Solar Cells. Adv. Mater. 2010, 22, 3839-3856. [CrossRef]

8. Søndergaard, R.R.; Hösel, M.; Angmo, D.; Larsen-Olsen, T.T.; Krebs, F.C. Roll-to-roll fabrication of polymer solar cells. Mater. Today 2012, 15, 36-49. [CrossRef]

9. O'Connor, T.F.; Zaretski, A.; Savagatrup, S.; Printz, A.; Wilkes, C.D.; Diaz, M.I.; Sawyer, E.J.; Lipomi, D.J. Wearable organic solar cells with high cyclic bending stability: Materials selection criteria. Sol. Energy Mater. Sol. Cells 2016, 144, 438-444. [CrossRef]

10. Jinno, H.; Fukuda, K.; Xu, X.; Park, S.; Suzuki, Y.; Koizumi, M.; Yokota, T.; Osaka, I.; Takimiya, K.; Someya, T. Stretchable and waterproof elastomer-coated organic photovoltaics for washable electronic textile applications. Nat. Energy 2017, 2, 780-785. [CrossRef] 
11. Kim, T.; Kim, J.-H.; Kang, T.E.; Lee, C.; Kang, H.; Shin, M.; Wang, C.; Ma, B.; Jeong, U.; Kim, T.-S.; et al. Flexible, highly efficient all-polymer solar cells. Nat. Commun. 2015, 6, 8547. [CrossRef]

12. Etxebarria, I.; Guerrero, A.; Albero, J.; Garcia-Belmonte, G.; Palomares, E.; Pacios, R. Inverted vs standard PTB7:PC70BM organic photovoltaic devices. The benefit of highly selective and extracting contacts in device performance. Org. Electron. 2014, 15, 2756-2762. [CrossRef]

13. Nam, S.; Hahm, S.G.; Han, H.; Seo, J.; Kim, C.; Kim, H.; Marder, S.R.; Ree, M.; Kim, Y. All-Polymer Solar Cells with Bulk Heterojunction Films Containing Electron-Accepting Triple Bond-Conjugated Perylene Diimide Polymer. ACS Sustain. Chem. Eng. 2015, 4, 767-774. [CrossRef]

14. Ma, W.; Yang, G.; Jiang, K.; Carpenter, J.H.; Wu, Y.; Meng, X.; McAfee, T.; Zhao, J.; Zhu, C.; Wang, C.; et al. Influence of Processing Parameters and Molecular Weight on the Morphology and Properties of High-Performance PffBT4T-2OD:PC71BM Organic Solar Cells. Adv. Energy Mater. 2015, 5, 1501400. [CrossRef]

15. Liu, Y.; Zhao, J.; Li, Z.; Mu, C.; Ma, W.; Hu, H.; Jiang, K.; Lin, H.; Ade, H.; Yan, H. Aggregation and morphology control enables multiple cases of high-efficiency polymer solar cells. Nat. Commun. 2014, 5, 5293. [CrossRef]

16. Cui, Y.; Yao, H.; Zhang, J.; Zhang, T.; Wang, Y.; Hong, L.; Xian, K.; Xu, B.; Zhang, S.; Peng, J.; et al. Over 16\% efficiency organic photovoltaic cells enabled by a chlorinated acceptor with increased open-circuit voltages. Nat. Commun. 2019, 10, 2515. [CrossRef]

17. Liao, H.-C.; Ho, C.-C.; Chang, C.-Y.; Jao, M.-H.; Darling, S.; Su, W.-F. Additives for morphology control in high-efficiency organic solar cells. Mater. Today 2013, 16, 326-336. [CrossRef]

18. Pearson, A.J.; Hopkinson, P.E.; Couderc, E.; Domanski, K.; Abdi-Jalebi, M.; Greenham, N.C. Critical light instability in CB/DIO processed PBDTTT-EFT:PC 71 BM organic photovoltaic devices. Org. Electron. 2016, 30, 225-236. [CrossRef]

19. Zhao, J.; Zhao, S.; Xu, Z.; Qiao, B.; Huang, D.; Zhao, L.; Li, Y.; Zhu, Y.; Wang, P. Revealing the Effect of Additives with Different Solubility on the Morphology and the Donor Crystalline Structures of Organic Solar Cells. ACS Appl. Mater. Interfaces 2016, 8, 18231-18237. [CrossRef]

20. Güldal, N.S.; Berlinghof, M.; Kassar, T.; Du, X.; Jiao, X.; Meyer, M.; Ameri, T.; Osvet, A.; Li, N.; Destri, G.L.; et al. Controlling additive behavior to reveal an alternative morphology formation mechanism in polymer: Fullerene bulk-heterojunctions. J. Mater. Chem. A 2016, 4, 16136-16147. [CrossRef]

21. Kim, Y.; Yeom, H.R.; Kim, J.Y.; Yang, C. High-efficiency polymer solar cells with a cost-effective quinoxaline polymer through nanoscale morphology control induced by practical processing additives. Energy Environ. Sci. 2013, 6, 1909. [CrossRef]

22. Li, M.; Gao, K.; Wan, X.; Zhang, Q.; Kan, B.; Xia, R.; Liu, F.; Yang, X.; Feng, H.; Ni, W.; et al. Solution-processed organic tandem solar cells with power conversion efficiencies $>12 \%$. Nat. Photon. 2016, 11, 85-90. [CrossRef]

23. Lee, K.H.; Schwenn, P.; Smith, A.R.; Cavaye, H.; Shaw, P.E.; James, M.; Krueger, K.B.; Gentle, I.R.; Meredith, P.; Burn, P.L. Morphology of All-Solution-Processed “Bilayer” Organic Solar Cells. Adv. Mater. 2010, 23, 766-770. [CrossRef] [PubMed]

24. Zhou, Y.; Gu, K.L.; Gu, X.; Kurosawa, T.; Yan, H.; Guo, Y.; Koleilat, G.I.; Zhao, D.; Toney, M.F.; Bao, Z. All-Polymer Solar Cells Employing Non-Halogenated Solvent and Additive. Chem. Mater. 2016, 28, 5037-5042. [CrossRef]

25. Jo, J.; Kim, S.-S.; Na, S.-I.; Yu, B.-K.; Kim, D.-Y. Time-Dependent Morphology Evolution by Annealing Processes on Polymer:Fullerene Blend Solar Cells. Adv. Funct. Mater. 2009, 19, 866-874. [CrossRef]

26. Min, J.; Kwon, O.K.; Cui, C.; Park, J.-H.; Wu, Y.; Park, S.Y.; Li, Y.; Brabec, C.J. High performance all-small-molecule solar cells: Engineering the nanomorphology via processing additives. J. Mater. Chem. A 2016, 4, 14234-14240. [CrossRef]

27. Nguyen, L.H.; Hoppe, H.; Erb, T.; Güneş, S.; Gobsch, G.; Sariciftci, N.S. Effects of Annealing on the Nanomorphology and Performance of Poly(alkylthiophene):Fullerene Bulk-Heterojunction Solar Cells. Adv. Funct. Mater. 2007, 17, 1071-1078. [CrossRef]

28. Radchenko, E.S.; Anokhin, D.V.; Gerasimov, K.L.; Rodygin, A.I.; Rychkov, A.A.; Shabratova, E.D.; Grigorian, S.; Ivanov, D.A. Impact of the solubility of organic semiconductors for solution-processable electronics on the structure formation: A real-time study of morphology and electrical properties. Soft Matter 2018, 14, 2560-2566. [CrossRef] 
29. Sanyal, M.; Schmidt-Hansberg, B.; Klein, M.; Colsmann, A.; Munuera, C.; Vorobiev, A.; Lemmer, U.; Schabel, W.; Dosch, H.; Barrena, E. In Situ X-Ray Study of Drying-Temperature Influence on the Structural Evolution of Bulk-Heterojunction Polymer-Fullerene Solar Cells Processed by Doctor-Blading. Adv. Energy Mater. 2011, 1, 363-367. [CrossRef]

30. Logothetidis, S. In situ characterization of organic electronic materials using X-ray techniques. In Handbook of Flexible Organic Electronics; Woodhead Publishing: Cambridge, UK, 2014; pp. 217-226. [CrossRef]

31. Güldal, N.S.; Kassar, T.; Berlinghof, M.; Ameri, T.; Osvet, A.; Pacios, R.; Destri, G.L.; Unruh, T.; Brabec, C.J. Real-time evaluation of thin film drying kinetics using an advanced, multi-probe optical setup. J. Mater. Chem. C 2016, 4, 2178-2186. [CrossRef]

32. Gu, X.; Reinspach, J.; Worfolk, B.; Diao, Y.; Zhou, Y.; Yan, H.; Gu, K.; Mannsfeld, S.; Toney, M.F.; Bao, Z. Compact Roll-to-Roll Coater for in Situ X-ray Diffraction Characterization of Organic Electronics Printing. ACS Appl. Mater. Interfaces 2016, 8, 1687-1694. [CrossRef] [PubMed]

33. Yao, S.; Zhu, Y. Nanomaterial-Enabled Stretchable Conductors: Strategies, Materials and Devices. Adv. Mater. 2015, 27, 1480-1511. [CrossRef]

34. O'Connor, B.; Kline, R.J.; Conrad, B.; Richter, L.J.; Gundlach, D.; Toney, M.F.; Delongchamp, D.M. Anisotropic Structure and Charge Transport in Highly Strain-Aligned Regioregular Poly(3-hexylthiophene). Adv. Funct. Mater. 2011, 21, 3697-3705. [CrossRef]

35. Mun, J.; Wang, G.-J.N.; Oh, J.Y.; Katsumata, T.; Lee, F.L.; Kang, J.; Wu, H.-C.; Lissel, F.; Rondeau-Gagné, S.; Tok, J.B.-H.; et al. Effect of Nonconjugated Spacers on Mechanical Properties of Semiconducting Polymers for Stretchable Transistors. Adv. Funct. Mater. 2018, 28, 1804222. [CrossRef]

36. Lu, C.; Lee, W.-Y.; Gu, X.; Xu, J.; Chou, H.-H.; Yan, H.; Chiu, Y.-C.; He, M.; Matthews, J.R.; Niu, W.; et al. Effects of Molecular Structure and Packing Order on the Stretchability of Semicrystalline Conjugated Poly(Tetrathienoacene-diketopyrrolopyrrole) Polymers. Adv. Electron. Mater. 2016, 3, 1600311. [CrossRef]

37. Grigorian, S.; Escoubas, S.; Ksenzov, D.; Duche, D.; Aliouat, M.; Simon, J.-J.; Bat-Erdene, B.; Allard, S.; Scherf, U.; Pietsch, U.; et al. A Complex Interrelationship between Temperature-Dependent Polyquaterthiophene (PQT) Structural and Electrical Properties. J. Phys. Chem. C 2017, 121, 23149-23157. [CrossRef]

38. Scenev, V.; Cosseddu, P.; Bonfiglio, A.; Salzmann, I.; Severin, N.; Oehzelt, M.; Koch, N.; Rabe, J.P. Origin of mechanical strain sensitivity of pentacene thin-film transistors. Org. Electron. 2013, 14, 1323-1329. [CrossRef]

39. Salari, M.; Joodaki, M.; Mehregan, S. Experimental investigation of tensile mechanical strain influence on the dark current of organic solar cells. Org. Electron. 2018, 54, 192-196. [CrossRef]

40. Cordill, M.J.; Glushko, O.; Kreith, J.; Marx, V.; Kirchlechner, C. Measuring electro-mechanical properties of thin films on polymer substrates. Microelectron. Eng. 2015, 137, 96-100. [CrossRef]

41. Aliouat, M.Y.; Escoubas, S.; Benoudia, M.C.; Ksenzov, D.; Duché, D.; Bènevent, E.; Videlot-Ackermann, C.; Ackermann, J.; Thomas, O.; Grigorian, S. In situ measurements of the structure and strain of a $\pi$-conjugated semiconducting polymer under mechanical load. J. Appl. Phys. 2020, 127, 045108. [CrossRef]

42. Gallard, M.; Amara, M.S.; Putero, M.; Burle, N.; Guichet, C.; Escoubas, S.; Richard, M.-I.; Mocuta, C.; Chahine, R.R.; Bernard, M.; et al. New insights into thermomechanical behavior of GeTe thin films during crystallization. Acta Mater. 2020, 191, 60-69. [CrossRef]

43. Krywka, C.; Sternemann, C.; Paulus, M.; Javid, N.; Winter, R.; Al-Sawalmih, A.; Yi, S.; Raabe, D.; Tolan, M. The small-angle and wide-angle X-ray scattering set-up at beamline BL9 of DELTA. J. Synchrotron Radiat. 2007, 14, 244-251. [CrossRef] [PubMed]

44. Li, N.; Perea, J.D.; Kassar, T.; Richter, M.; Heumueller, T.; Matt, G.J.; Hou, Y.; Güldal, N.S.; Chen, H.; Chen, S.; et al. Abnormal strong burn-in degradation of highly efficient polymer solar cells caused by spinodal donor-acceptor demixing. Nat. Commun. 2017, 8, 14541. [CrossRef]

45. Zhang, C.; Heumueller, T.; Gruber, W.; Almora, O.; Du, X.; Ying, L.; Chen, J.; Unruh, T.; Cao, Y.; Li, N.; et al. Comprehensive Investigation and Analysis of Bulk-Heterojunction Microstructure of High-Performance PCE11:PCBM Solar Cells. ACS Appl. Mater. Interfaces 2019, 11, 18555-18563. [CrossRef] [PubMed]

46. Scherrer, P. Bestimmung der Größe und der inneren Struktur von Kolloidteilchen mittels Röntgenstrahlen. Nachr. Ges. Wiss. Göttingen 1918, 1918, 98-100. Available online: http://eudml.org/doc/59018 (accessed on 20 June 2020). 
47. Treat, N.D.; Chabinyc, M.L. Phase Separation in Bulk Heterojunctions of Semiconducting Polymers andFullerenes for Photovoltaics. Annu. Rev. Phys. Chem. 2014, 65, 59-81. [CrossRef] [PubMed]

48. Liu, C.-M.; Su, Y.-W.; Jiang, J.-M.; Chen, H.-C.; Lin, S.-W.; Su, C.-J.; Jeng, U.-S.; Wei, K.-H. Complementary solvent additives tune the orientation of polymer lamellae, reduce the sizes of aggregated fullerene domains, and enhance the performance of bulk heterojunction solar cells. J. Mater. Chem. A 2014, 2, 20760-20769. [CrossRef]

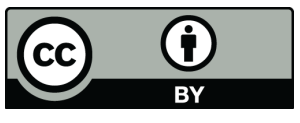

(C) 2020 by the authors. Licensee MDPI, Basel, Switzerland. This article is an open access article distributed under the terms and conditions of the Creative Commons Attribution (CC BY) license (http://creativecommons.org/licenses/by/4.0/). 